\title{
DEBILIDADE MENTAL: O PATINHO FEIO DA CLÍNICA PSICANALÍTICA*
}

\author{
Daniele Rosa Sanches e Manoel Tosta Berlinck
}

Daniele Rosa Sanches
Psicóloga,
psicanalista, mestre
em Psicologia
Clínica pela
PUC-SP, docente
e supervisora
clínica da Uniban-
SP e membro
do Fórum do
Campo Lacaniano
em São Paulo.
Manoel Tosta Berlinck
Sociólogo,
psicanalista,
Ph.D pela Cornell
University,
professor de Pós-
Graduação em
Psicologia Clínica
da PUC-SP, diretor
do Laboratório
de Psicopatologia
Fundamental e
editor da revista
Latinoamericana
de Psicopatologia
Fundamental.

Daniele Rosa Sanches psicanalista, mestre em Psicologia Clínica pela PUC-SP, docente e supervisora clínica da UnibanSP e membro do Fórum do Campo Lacaniano Sociólogo psicanalista University, professor de PósGraduação em Psicologia Clínica da PUC-SP, diretor do Laboratório de Psicopatologi Fundamental e Latinoamericana Fundamental.
RESUMO: A debilidade mental permanece com etiologia obscura, e hoje em dia é definida pela psiquiatria como o grau mais leve de todos os retardos mentais (QI entre 50 e 70). Além desta classificação métrica, a Clínica Psicanalítica define a Debilidade Mental como uma posição psíquica encontrada tanto em indivíduos saudáveis biologicamente quanto em portadores de alguma deficiência neurológica. Por esta concepção, a psicanálise pode contribuir ao debate do tema.

Palavras-chave: debilidade mental, posição psíquica, inibição intelectual, retardo mental.

ABSTRACT: Mental debility: the ugly duckling of the psychoanalytical clinic. Nowadays the origin of Mental Debility is not clear. Mental Debility is defined by psychiatry as the lowest level of all Mental Retardations (IQ ranging from 50 to 70). Besides this metric assessment, the psychoanalytic clinic defines Mental Debility as a psychic position established in both biologically healthy individuals as well as in individuals with some kind of neurologic deficiency. Therefore, psychoanalysis may have a contribution to this discussion.

Keywords: Mental Debility, psychic position, intellectual inhibition, mental retardation.

\footnotetext{
* Pesquisa realizada no Laboratório de Psicopatologia Fundamental com auxílio do CNPq.
} 
Depois de avistar os lindos e imponentes cisnes brancos no lago

o patinho feio olhou seu reflexo na água e...

0 que é debilidade mental? O conceito de debilidade mental é diferentemente definido por dois campos de atuação: a psiquiatria e a psicanálise. $\mathrm{Na}$ concepção psiquiátrica, a debilidade mental é definida dentro da categoria de Retardo Mental. Pela psicanálise, a definição se constituiu a partir da escuta de uma diferenciada posição psíquica.

\title{
NOTAS SOBRE A CONCEPÇÃO PSIQUIÁTRICA DA DEBILIDADE MENTAL
}

Atualmente, o campo patológico que se refere ao comprometimento da inteligência é chamado Retardo Mental. O Retardo Mental é subdividido em diferentes níveis de gravidade e, dentre eles, a debilidade mental representa o nível mais leve de comprometimento. Para abordar a categoria da debilidade em sua especificidade, antes se faz necessária uma apresentação da definição do campo geral do Retardo Mental, considerado em relação ao conceito de inteligência. Sendo a conceituação da noção de "inteligência” muito ampla, os órgãos de saúde elegeram algumas habilidades para defini-la. A Organização Mundial de Saúde (CID 10) delimita um pouco o conceito de inteligência e atribui ao Retardo Mental a seguinte definição, com seu respectivo código:

\begin{abstract}
"Retardo mental (F70-F79). Parada no desenvolvimento ou desenvolvimento incompleto do funcionamento intelectual, caracterizados essencialmente por um comprometimento durante o período de desenvolvimento das faculdades que determinam o nível global de inteligência, isto é das funções cognitivas, de linguagem, da motricidade e do comportamento social. O retardo mental pode acompanhar um outro transtorno mental ou físico, ou ocorrer de modo independente." (CID 10, 2003, p.361)
\end{abstract}

Na tentativa de delimitação da noção global de inteligência surgem conceitos auxiliares para o diagnóstico do Retardo, como, por exemplo, o de “funcionamento adaptativo” encontrado na seguinte definição: “o Retardo Mental pode ser diagnosticado em pessoas com QIs de aproximadamente 70 ou abaixo se elas demonstrarem déficits significativos em pelo menos duas áreas do funcionamento adaptativo” (KAPLAN e SADOCK, 2003, p.2405). Por "funcionamento adaptativo" entende-se a efetividade com que o indivíduo realiza sua independência e a responsabilidade social esperada para sua idade e ambiente cultural. O referido funcionamento seria regulado por inúmeras variáveis, dentre elas a educação, as oportunidades sociais e afetivas, as carac- 
terísticas individuais da personalidade, bem como por transtornos mentais e eventuais condições médicas.

Ainda sobre a definição geral de Retardo Mental, o Manual Diagnóstico e Estatístico de Transtornos Mentais, em sua quarta edição (DSM IV), prevê três critérios para a realização do teste diagnóstico, especificando ainda mais o conceito de funcionamento adaptativo:

“A característica essencial do Retardo Mental é um funcionamento intelectual significativamente inferior à média (Critério A), acompanhado de limitações significativas no funcionamento adaptativo em pelo menos duas das seguintes áreas de habilidades: comunicação, autocuidados, vida doméstica, habilidades sociais/ interpessoais, uso de recursos comunitários, autossuficiência, trabalho, lazer, saúde e segurança (Critério B). O início deve ocorrer antes dos 18 anos (Critério C).” (DSM IV,1995, p.39)

Além dessas definições gerais, o diagnóstico do Retardo pressupõe também uma especificação quanto ao nível de gravidade do atraso mental do paciente, sendo que "quatro níveis de gravidade podem ser especificados refletindo o atual nível de prejuízo intelectual: leve, moderado, severo, profundo” (DSM IV, 1995, p.40).

A localização do nível de gravidade do retardo do paciente entre esses quatro níveis é feita principalmente pela delimitação do seu QI. O QI (coeficiente de inteligência) é avaliado por testes psicométricos, chamados "baterias" ou escalas de inteligência. Esses testes são padronizados, sua aplicação é individual e dentre eles são citadas pelo DSM IV (1995) e pela maioria dos tratados de psiquiatria as Escalas Weschler de Inteligência para Crianças (revisada); a Escala de Inteligência Stanford-Binet; e a Bateria Kauffman de Avaliação para Crianças.

Devemos observar, entretanto, que as definições para o Retardo Mental não se restringem à escala de QI — pelo contrário, se esforçaram por elencar critérios e habilidades considerando aspectos culturais e educacionais, bem como condições médicas gerais apresentadas pelo paciente a ser diagnosticado.

Os testes psicométricos não existiram desde sempre, e sua história está relatada de forma completa na pesquisa de Santiago (2005). Nesse percurso histórico os testes psicométricos são relativamente recentes, mas a classificação das perturbações da inteligência em níveis de gravidade, não. Conforme Ajuriaguerra (1978), antigamente, o campo global da inteligência era chamado campo das "funções superiores" e o nível de comprometimento dessas funções era estabelecido por avaliação clínica. O prejuízo intelectual era, portanto, igualmente definido por níveis de gravidade, que, do mais leve ao mais grave, possuíam a seguinte nomenclatura, respectivamente: debilidade mental, imbecilidade e idiotia. Essa nomenclatura foi desgastada pelo mau uso, pois 
extrapolou o âmbito médico e passou a figurar na linguagem cotidiana como referência pejorativa.

Com o intuito de retirar a noção depreciativa da categoria e nomeá-la com maior cientificidade, o termo 'oligofrenia' apresentou-se como opção de substituto. A palavra se origina do grego oligos = pouco e phren = espírito. Dessa forma, oligofrenia representaria a ideia de que se tratava de uma categoria sobre os níveis de 'fraqueza mental'. Assim, a debilidade mental passou a ser chamada de 'oligofrenia leve', a imbecilidade, de 'oligofrenia moderada', e a idiotia, de 'oligofrenia grave'.

A preocupação com a nomenclatura foi acompanhada pelos esforços em educar e melhor caracterizar melhor esses pacientes. Nesse contexto, advieram a educação especial e os testes psicométricos. Estes últimos permitiram um fortalecimento da noção de inteligência; já a educação especial, por ter realizado uma melhora em quadros clínicos antes entendidos como irrecuperáveis e ineducáveis, trouxe uma nova perspectiva prognóstica ao campo das oligofrenias, conforme relata Santiago (2005). A partir desse avanço os níveis de comprometimento da inteligência passaram a ser concebidos como níveis de atraso no desenvolvimento dessa faculdade, ou seja, níveis de retardo. Dessa forma, a perspectiva do atraso representada pelo termo 'Retardo' associada a uma divisão psicométrica deste grupo da categoria pelos testes de QI provocou a atual subdivisão da categoria, apresentada abaixo com seus respectivos códigos de identificação do DSM IV (1995, p.40):

“. Código 317 - Retardo Mental Leve: nível de QI 50-55 a aproximadamente 70 (antiga Oligofrenia Leve ou Debilidade Mental)

. Código 318.0 - Retardo Mental Moderado: nível de QI de 35-40 a 50-55 (antiga Oligofrenia Moderada ou Imbecilidade)

. Código 318.1 — Retardo Mental Severo: nível de QI de 20-25 a 35-40.

(antiga Oligofrenia Moderada ou Imbecilidade)

. Código 318.2 - Retardo Mental Profundo: nível de QI abaixo de 20 ou 25 (antiga Oligofrenia Profunda)"

Os antigos sinônimos foram acrescentados aqui voluntariamente ao lado da classificação do DSM IV (1995) para comparação do leitor. A nomenclatura original, apesar das tentativas de substituição, nunca foi inteiramente substituída em seu uso corrente, motivo pelo qual autores atuais relatam as subcategorias de maneira a apresentá-las com seus sinônimos históricos. Essa preocupação em incluir antigos termos ainda usados é encontrada em Dalgalarrondo, (2000) que fornece a seguinte definição para a debilidade mental, enfim apresentada em sua especificidade: 
“Retardo Mental Leve: Também denominado Oligofrenia Leve ou Debilidade Mental: Os indivíduos que apresentam este grau de retardo revelam nos testes de inteligência um QI na faixa de 50 a 69. A idade mental do adulto corresponde a uma criança de cerca de 9 a 12 anos. Uma etiologia orgânica raramente é encontrada. Este é o grupo mais frequente de pessoas com retardo mental, compreendendo cerca de $85 \%$ de todos os casos de indivíduos com retardo mental." (2000, p.175)

Além da apresentação em sua particularidade, a definição de debilidade mental chama a atenção para o dado que traz consigo: quase $90 \%$ de todos os casos de Retardo são casos de Retardo Leve (Debilidade Mental), e nessa enorme fatia raramente um déficit orgânico é encontrado. Esses dados são demasiadamente expressivos e evidenciam, sobretudo, que dentro do vasto campo dos Retardos Mentais a questão etiológica é uma das mais complexas e obscuras.

Todos os níveis de Retardo historicamente foram categorizados como perturbação da inteligência de origem orgânica, critério esse que impunha a diferença dessa categoria para a categoria das psicoses, por exemplo, consideradas de origem psíquica. No entanto, com o avanço da tecnologia médica, a antes inabalável suposição na etiologia orgânica para todos os níveis de Retardo tem sido obrigatoriamente revista, principalmente ao nível do Retardo Leve (Debilidade Mental): “Quanto mais severo o grau de prejuízo cognitivo, maior a probabilidade de que uma causa específica seja descoberta" (KAPLAN e SADOCK, 1999, p.24010).

O DSM IV (1995) elenca os fatores que causariam déficits orgânicos, dentre eles a hereditariedade (síndrome do X frágil e erros inatos do metabolismo), as alterações precoces do desenvolvimento embrionário (síndrome de Down devido à trissomia do 21 e danos pré-natais causados por toxinas), problemas de gravidez e perinatais (desnutrição, infecções, hipóxia e traumas ) e condições médicas gerais adquiridas no início da infância causadas por infecções, traumas e envenenamentos. Ao lado desses fatores de incidência orgânica direta, o manual não deixa de classificar com igual peso etiológico fatores de influências ambientais e psíquicas, tais como privação de afeto e cuidados, estimulação social, linguística e educação, além dos diversos transtornos mentais, citando o autismo como exemplo.

As possibilidades etiológicas são vastas, e nesse sentido parece ser consenso na literatura psiquiátrica que, a despeito da etiologia principal, o grau de a gravidade do Retardo é determinada por uma combinação de fatores psíquicos, ambientais e orgânicos, exceto em casos de lesões maciças ou de síndromes genéticas avassaladoras, nas quais as impossibilidades de funcionamento do SNC imperam sobre quaisquer tentativas de estimulação social, psicomotora ou de investimento afetivo. 
Diante de uma gama enorme de fatores que podem ser considerados para investigar a etiologia do Retardo em qualquer um de seus níveis, a American Association on Mental Retardation (AAMR), em sua mais nova edição (AAMR, 2006) preocupou-se em transmitir aos seus leitores a evolução da definição de retardo mental com o passar dos anos. As modificações são referentes tanto à hipótese de etiologia quanto ao entendimento da manifestação propriamente dita. O capítulo destinado a apresentar as alterações é aberto com o seguinte quadro comparativo (AAMR, 2006, p.29):

Definição de 1908: Um estado de Deficiência Mental de nascença, ou a partir de tenra Idade devido a desenvolvimento cerebral incompleto em consequência do qual a pessoa afetada é incapaz de realizar seus deveres como membro da sociedade na posição da vida para a qual ela nasceu (TREDGOLD, 1908).

Definição de 2000: Retardo Mental é uma incapacidade caracterizada por importantes limitações tanto no funcionamento intelectual quanto no funcionamento adaptativo. Está expresso nas habilidades adaptativas conceptuais, sociais e práticas. Essa incapacidade tem início antes dos 18 anos (AAMR, 2000).

Conforme podemos observar, a primeira definição se esforça para localizar o Retardo como efeito do desenvolvimento cerebral incompleto - inclusive, a própria nomenclatura "deficiência mental” refere-se à antiga e exclusiva aposta na etiologia orgânica. Já a segunda definição, do ano 2000, sequer arrisca definir uma etiologia, dizendo apenas que o Retardo é manifestação de uma incapacidade que se expressa antes dos 18 anos.

Essa breve exposição mostra a evolução da definição de Retardo, bem como a revisão nas apostas etiológicas da patologia, que antes eram concentradas nos déficits orgânicos. Considerada dentro dessa amplitude etiológica, a debilidade mental não deixa de surpreender por representar $85 \%$ de todos os casos de Retardo, fatia atualmente sem qualquer indício da presença de um déficit orgânico. Desta maneira, a maioria dos casos não pode mais ter sua histórica paternidade orgânica reconhecida.

Parcialmente privada de sua “orgânica família de origem”, a debilidade mental se vê órfã e passa a figurar no "ninho” das perturbações mentais de provável origem psíquica. No entanto, nem todos acompanham essa nova perspectiva etiológica para a categoria da debilidade mental, que então mergulha numa incógnita sobre sua origem.

A obscuridade etiológica tem efeito prático devastador. A não constatação de um defeito orgânico na maioria dos casos de debilidade mental provoca uma suposição dos psiquiatras de que o atraso mental em questão se deve a fatores psíquicos em conjunto com aos sociais. Com essa hipótese alguns médicos en- 
caminham seus pacientes débeis às clínicas psicológicas. No entanto, a maioria das clínicas "psis", por sua vez, desconhece a possibilidade da debilidade mental ser um fenômeno de origem psíquica, ou ao menos que fatores psíquicos possam ser determinantes.

Assim, há casos em que o paciente já chega aos consultórios psicológicos com o diagnóstico médico de débil, e muitas vezes, o diagnóstico psicológico imediato dado como correlato é o de psicose, como se fossem condições equivalentes. Já algumas clínicas encaminham novamente o paciente para mais uma bateria de exames neurológicos, pois ainda estão paradas na definição do século anterior. Desconhecendo que o diagnóstico da debilidade não precisa estar vinculado a uma deficiência neurológica, alguns consultórios "psis” querem saber a noção exata da "área afetada”, para que então consigam trabalhar "separando" o que é da ordem psíquica daquilo que seria da ordem neurológica. O empenho em separar psiquismo e corpo é infértil e a dúvida permanece.

A dúvida etiológica, que deveria acarretar um aprofundamento na investigação clínica do fenômeno é, ao contrário, subvertida e se torna um “jogo de empurra”. Muitas vezes, o único denominador comum encontrado por médicos, psicólogos e psicanalistas nestes casos é o recuo clínico e o encaminhamento à Educação Especial. Neste destino, os pacientes tornam-se alunos eternos e ser educado passa a consistir em sua prescrição única de existência. Com esta prescrição exclusivamente pedagógica, a dimensão clínica do fenômeno é esquecida e o sofrimento psíquico destes pacientes deixa de ser escutado.

A partir daqui deixamos o âmbito médico e vamos à definição da debilidade mental através da clínica psicanalítica, cujo principal indicador diagnóstico é uma submissão diferente e radical do sujeito do inconsciente ao Outro.

\section{A CONCEPÇÃO PSICANALÍTICA DA DEBILIDADE MENTAL}

Na literatura psicanalítica raramente encontra-se referência ao termo Retardo, ou mesmo a qualquer uma de suas especificações, como "retardo leve", por exemplo. No entanto, menos rara é a referência ao termo "debilidade mental". Sublinha-se aqui "termo", pois é mais a este e menos à categoria que a teoria psicanalítica se refere para nomear uma particular posição psíquica observada clinicamente. Dessa forma, apesar de se referir ao termo psiquiátrico, a partir da escuta clínica a teoria psicanalítica construiu uma definição particular para a noção de "debilidade mental".

Para a psicanálise, a definição do conceito de debilidade mental não considera dentre seus critérios a localização do paciente na escala de QI. O paciente débil, no contexto da clínica psicanalítica, seria um sujeito cuja manifestação psíquica revela uma relação ao Outro estabelecida de modo tão submisso a tal ponto de o sujeito estar impedido de se orientar pelo próprio desejo. Trata-se, portanto, 
de um sujeito sempre funcionando de modo a responder às demandas alheias, funcionamento que revela uma posição psíquica particular e diferenciada. Mas reconhecer esta posição e diagnosticá-la é muito difícil, por dois motivos.

Primeiro, o desconhecimento da debilidade mental como uma possível expressão patológica de origem psíquica faz com que esta nunca seja uma hipótese diagnóstica lembrada pelos psicanalistas. Desse modo, o primeiro desafio é o próprio reconhecimento da existência dessa manifestação clínica. Em segundo lugar, há o problema do erro diagnóstico. Se, de um lado, a debilidade mental é uma ilustre desconhecida do campo psicanalítico, de outro, o sujeito de posição débil não passa despercebido à escuta do psicanalista, que nota em seu paciente um uso particular da linguagem. O modo estranho e copiado com que fala o sujeito débil implica frequentemente diagnósticos errôneos.

A debilidade mental num paciente neurótico não raro apresenta para a clínica um sujeito cujos chistes cometidos lhe são inacessíveis. Nos sujeitos de posição subjetiva débil geralmente é revelada uma fala de aparência caricatural, não metaforizável e de aspecto padronizado. Ou seja, nestes casos, apresenta-se ao clínico uma manifestação similar àquela trazida pela psicose, não quanto aos sintomas delirantes e alucinatórios, mas principalmente quanto ao modo “mecânico e padronizado” como fala o sujeito. Por essas características, quando tais pacientes psiquicamente débeis chegam aos consultórios “psis”, os clínicos, muitas vezes, precipitam o diagnóstico de psicose. Em alguns casos, de fato, trata-se de uma psicose; no entanto, em outros, não.

O erro em diagnosticar uma debilidade como uma psicose, erro induzido principalmente pelos fenômenos de fala presentes no sujeito débil, pode trazer consequências drásticas na direção do tratamento, bem como nas possibilidades de intervenção com aquele sujeito. Pretende-se aqui concentrar a atenção para os casos em que a debilidade encobriria a estrutura neurótica subjacente. São essas as maiores vítimas dos erros diagnósticos. Mas, apesar deste foco, é válido notar que, quando se trata verdadeiramente de uma psicose associada a uma debilidade, geralmente apresentam-se sujeitos de uma gravidade incomum alguns desses casos, inclusive, evidenciam uma extrema dificuldade dos sujeitos em relação ao controle corporal e funções fisiológicas voluntárias, mesmo se tratando de pacientes biologicamente saudáveis.

A abordagem do campo da psicose levaria a uma discussão que tenderia a diferenciar sujeitos psicóticos mentalmente retardados daqueles nos quais não há um comprometimento evidente. Mesmo com tal diferença, as psicoses parecem, de modo geral, conter uma debilidade, mas nem toda debilidade representa uma psicose. Não entraremos nesse debate, mas sua menção é válida apenas para indicar uma cautela a ser empregada antes de fazer da debilidade uma correlata da psicose. Dessa maneira, a despeito de observar no sujeito a 
presença de uma debilidade, para o psicanalista ainda restaria a tarefa de escutar qual estrutura clínica é mascarada por aquele fenômeno; isso, numa leitura que carrega a especificidade da vertente lacaniana.

Miranda (2002) investigou em sua pesquisa justamente a característica da debilidade de camuflar a estrutura do sujeito, e nomeou a debilidade mental como "máscara da estrutura". Seu texto traz contribuições clínicas que revelam a debilidade presente nas estruturas neuróticas, psicóticas e perversas. No entendimento desta autora:

"A debilidade mental é uma posição do sujeito frente à falta apreendida por ele na relação especular com o Outro primordial e pode ocorrer nas três estruturas, uma vez que estas são determinadas pelo significante. Na neurose, a posição imaginária manteria a relação especular com a mãe, sustentando um 'não quero saber que eu e mamãe não somos um'. Na psicose e na perversão, seria a máscara última antes do desvelamento da estrutura." (MIRANDA, 2002, p.39)

Além do entendimento da debilidade como uma posição que vela a falta no Outro, se destaca nessa definição da autora, por meio da imagem evocada pelo termo de "máscara", mais uma referência ao problema do diagnóstico, imposto ao psicanalista pela presença da debilidade. Assim, conforme vem sendo apresentada até aqui, a debilidade está inevitavelmente submersa na questão da dificuldade diagnóstica, seja pelo não reconhecimento, por parte dos psicanalistas, da existência desse tipo de manifestação, seja por sua própria expressão clínica que camufla a estrutura.

Para além de sua obscuridade, a identificação da debilidade pode ser feita por algumas características observadas clinicamente. A escuta clínica identifica um sujeito como débil por se apresentar débil quanto ao próprio desejo. O débil não assume o próprio desejo, não o reconhece e o mantém exilado. Nessa posição psíquica tomada de modo radical o sujeito toma como seu o desejo alheio, executando aquilo que o Outro lhe demandar.

Sim, poderíamos pensar que a psicose revela um sujeito igualmente aprisionado ao campo do Outro; entretanto, a debilidade manifesta num sujeito neurótico não o faz posicionar-se exatamente fora do discurso, tal como ocorre na psicose. Sabemos, através da teoria lacaniana, que um discurso, dentre outras propriedades, também representa a forma de laço social feita pelo sujeito e o modo pelo qual ele opera com o saber inconsciente. Nesse sentido, elaborando a respeito dessa diferença discursiva, são esclarecedoras as palavras do psicanalista Laurent:

"Existe uma relação particular do ser sem o saber a que se pode chamar debilidade. O sujeito se situa com efeito quanto ao saber numa relação de evidência de nada 
compreender, numa relação de exterioridade. E no entanto, o sujeito débil não se situa ao contrário do sujeito psicótico fora do discurso.” (1989, p.131)

Ao realizar essa distinção, também poderíamos pensar que um simples neurótico também se coloca longe de seu saber e faz valer o desejo do Outro. Entretanto, nem que seja por um instante - um instante de destituição subjetiva, ou, ao contrário, um instante de elaboração —, o simples neurótico apreende seu engano e consegue ao menos ter uma notícia de seu desejo. Já no débil, esse engano raramente consegue ser capturado.

Seguindo na tentativa de caracterização da manifestação, a debilidade pode ser reconhecida naquele sujeito que não questiona o que as palavras querem dizer. O débil apenas acolhe as palavras como nomes próprios, como representantes absolutas de um único e verdadeiro sentido. Além disso, um dos principais indicadores diagnósticos que denuncia a debilidade está no próprio modo de falar do sujeito, que reproduz a fala da tevê, dos pais ou dos colegas, como se fossem produções suas. A paciente E., de 14 anos, nos dá um exemplo: “eu sou adolescente. Eu dou muito trabalho na escola porque as adolescentes dão muito trabalho. Eu só uso roupa preta que é de adolescente. E eu vou namorar adoidado, porque as adolescentes namoram e transam. A Adolescência é uma fase muito difícil”. Nessas falas “prontas, genéricas”, o débil muitas vezes propaga a fala do Outro sem qualquer toque de individualidade, mas o declama como seu mais íntimo e legítimo produto.

Em outros termos, o sujeito revela ao clínico sua posição débil ao comprar de modo cego e inquestionável aquilo que os outros falam, e isso caracteriza boa parte do que se quer dizer com "uma posição psíquica de submissão ao Outro, à fala do Outro". Nesse sentido, a debilidade mental é também reconhecida clinicamente pelo uso extremamente inocente que o sujeito faz da linguagem, acolhendo os dizeres do mundo como verdades absolutas, sem conseguir extrair desses dizeres o sentido de suas entrelinhas.

Neste contexto, o termo "debilidade mental" representa uma particular posição do sujeito anunciada principalmente pelo estranho uso inequívoco da linguagem. Assim, a posição débil pode até se apresentar num sujeito de QI considerado normal, mas que clinicamente não consegue captar o próprio chiste, entender o tom de uma ironia ou sequer consegue captar o duplo sentido de uma piada.

A particular posição psíquica referida aqui pressupõe, portanto, uma submissão do sujeito à fala e ao saber alheios de forma muito radical. É em função desta posição que os débeis comumente expressam-se como sujeitos caricaturais. No entanto, nem todos os casos de debilidade são tão explícitos assim. A debilidade do sujeito pode não se apresentar de modo tão claro, pode ser mais sutil, um pouco menos comprometedora. Ainda assim, de forma mais ou menos explícita, 
a clínica com a debilidade em essência revela sempre uma impossibilidade do sujeito de acessar seu saber inconsciente e seu próprio desejo, características que por si são suficientes para causar uma grande dificuldade de diagnóstico e manejo clínico.

\section{ALGUNS ASPECTOS METAPSICOLÓGICOS DA POSIÇÃO DÉBIL}

Considerada como o reflexo dessa peculiar posição psíquica de submissão do sujeito, é válido novamente enfatizar que, sob essa lente, a debilidade nem sempre está presente num paciente diagnosticado com retardo leve ou grave pelo teste de QI. Igualmente, ela não necessariamente está presente em todos os pacientes com problemas neurológicos ou com danos funcionais.

Alguns pacientes comprometidos em seu funcionamento cerebral por alguma síndrome genética ou lesão podem ser incrivelmente saudáveis, nada débeis, do ponto de vista psíquico. Já alguns pacientes organicamente perfeitos podem apresentar uma posição psíquica débil. No entanto, é fato clínico que muitos pacientes com lesões ou síndromes, por exemplo, paralisia cerebral e síndrome de Down, apresentam-se psiquicamente débeis. Poderíamos nos perguntar o porquê deste fato, se não há relação intrínseca entre a posição débil e o déficit orgânico. Ocorre que, frequentemente, quem vem ao mundo com alguma deficiência neurológica, de imediato não é acolhido como senhor de seus próprios desejos. Com esta predestinação, é comum estar reservada a esses sujeitos uma condição de serem sempre submetidos aos desejos e às demandas do Outro, ato que lhes proporciona fácil acesso a um funcionamento de abdicar de suas próprias escolhas e de executar o próprio desejo, tornando-se difícil escapar da debilidade; essa discussão é trabalhada na pesquisa de Sanches (2008).

O mecanismo psíquico que leva o sujeito a adotar tal posição submissa que implicará na debilidade é tema de debates desde 1964. Naquela época, a debilidade não era ainda entendida exatamente como uma posição subjetiva, mas havia esforços de teorizá-la como um fenômeno psíquico.

A definição clínica do débil passou a ser mais comum no âmbito psicanalítico quando Mannoni, em 1964, publicou seu livro A criança retardada e a mãe. O grande salto de Mannoni foi propor ao longo do livro que o débil, com ou sem o déficit orgânico, é um sujeito digno de escuta e, mais do que isso, que a debilidade mental poderia ter um sentido a ser escutado e tratado clinicamente.

Se com Mannoni o sujeito débil deveria ganhar "um lugar ao sol" da escuta clínica, com Lacan, nas raras menções feitas ao tema, a hipótese metapsicológica começou a ser elaborada por meio do que ele, em 1964, chamou de holófrase significante do par S1-S2 (p.225). Genérica e superficialmente, na teoria lacaniana a noção de holófrase refere que o saber inconsciente do sujeito (o S2) está comprometido, está colado ao primeiro traço de identificação do sujeito (o S1). 
Como sabemos, o primeiro traço de identificação do sujeito advém do Outro. Esta hipótese foi uma das primeiras a oferecer um alicerce metapsicológico àquela constatação clínica, já apresentada aqui, de que o débil toma o saber do Outro como verdade íntima e literal de si mesmo.

Neste debate metapsicológico, quando Lacan faz alusão ao tema logo se ocupa em citar a psicossomática ao lado da debilidade, acentuando que em ambas “certamente ocorre algo da mesma ordem da psicose” (1964, p.223).

Sabemos que "algo" não se equivale ao "todo", mas essa separação parece ser justamente a tarefa esquecida pela clínica atual que, como já mencionado, não hesita em extrair da manifestação da debilidade um diagnóstico de psicose. Com este frequente erro diagnóstico, a debilidade enquanto fenômeno clínico fica de lado, rejeitada, desconhecida, sendo somente alimentada por obsoletos mitos acoplados ao seu nome.

Ao olharmos o obscuro fenômeno mais de perto nota-se que o desconhecimento sobre a debilidade como manifestação psíquica revela também uma grande dificuldade de entendimento da questão ao nível metapsicológico. Afinal, em não se tratando de uma manifestação exclusiva dos sujeitos que portam uma deficiência neurológica, podendo expressar-se em sujeitos saudáveis biologicamente, então, a debilidade mental poderia ser um recurso psíquico? Qual? Sintoma? Defesa? Inibição? Mannoni (1964) propõe o seguinte caminho: “A debilidade concebida como um déficit capacitário isola o sujeito em sua deficiência. Procurando para a debilidade uma causa definida, nega-se que ela possa ter um sentido, quer dizer, uma história, ou que ela possa corresponder a uma situação” (MANNONI, 1964, p.39).

Ao postular que, seja a causa qual for, a debilidade tem um sentido, uma história e pode corresponder a uma situação, a autora caminhou para conferir à debilidade o status freudiano de sintoma. Já Lacan, nas raras menções feitas ao tema, refere-se à debilidade marcando a similaridade e, principalmente, a diferença quanto à psicose. Esta comparação “psicose e debilidade” pressupõe uma ressalva: uma estaria na ordem da estrutura, e a outra, na ordem de um fenômeno ocasionado por determinada posição inconsciente do sujeito.

Apesar da necessidade da retificação, a comparação "psicose e debilidade" pode indicar que o fenômeno débil seria engendrado no início da constituição psíquica, já que é comparado a uma estrutura clínica (a psicose). Nessa perspectiva, a debilidade não seria resultado de uma formação inconsciente posterior, tal como é o sintoma ou o processo de inibição, mas teria sua origem nos primórdios da constituição psíquica. Este entendimento pode ser extraído do Seminário de Lacan (1964) quando menciona a debilidade mental no contexto das duas operações inaugurais do sujeito: a alienação e a separação. Tal interpretação de leitura, entretanto, não oferece grande compreensão sobre a 
questão e os autores são obrigados a criar suas próprias hipóteses metapsicológicas acerca do fenômeno.

No levantamento dessas hipóteses há, por exemplo, a proposta que entende a debilidade mental por meio do processo de inibição intelectual. O resgate do conceito de inibição para pensar metapsicologicamente a debilidade se fez a partir do enlace com a Educação Especial, conforme mostra Santiago (2005). A pesquisa da autora problematiza o fato de que alunos com problemas de aprendizagem, matriculados na educação regular, são encaminhados indiscriminadamente às classes e escolas especiais com o diagnóstico de Retardo. Tornou-se escolar o que deveria ser um diagnóstico médico.

A psicanálise oferece escuta a muitos desses casos, revelando que muitos alunos diagnosticados como débeis são tratados clinicamente e seu atraso intelectual se desfaz, pois na verdade refere-se a uma inibição intelectual por algum motivo psíquico.

O motivo psíquico, desde Freud, é o saber inconsciente sobre a castração e a sexualidade. Algumas crianças inibidas trazem dificuldades pedagógicas e sociais até maiores do que alunos com comprometimentos por síndromes genéticas ou lesões cerebrais. Nesse ponto, inibição intelectual e debilidade mental se equivaleriam pela gravidade dos quadros de inibição. Assim, o conceito freudiano de inibição é resgatado como uma alternativa de equivalência para pensar os fundamentos metapsicológicos da debilidade mental.

Santiago (2005) realizou uma pesquisa aprofundada sobre o tema, oferecendo à literatura psicanalítica uma das raras exposições completas a este respeito, e é uma das autoras que propõe o entendimento da debilidade mental por meio do conceito de inibição intelectual: “Precisamente no ponto em que se anuncia como parte fundamental da estrutura a debilidade apresenta, no fundo, a mesma lógica constitutiva da função inibitória” (SANTIAGO, 2005, p.187).

Essa também é a proposta oferecida por outra autora, Cordié (2003), que em seu livro Los retrasados no existen apresenta como tese principal, conforme o próprio título anuncia, que os casos de retardo sem comprometimento neurológico na verdade não existem, pois são em última instância casos de inibição intelectual.

O entendimento metapsicológico da debilidade mental por meio do conceito de inibição gera questionamentos, e não é consenso entre os autores. Miranda, por exemplo, é clara ao afirmar seu entendimento de que a debilidade mental e a inibição são processos distintos:

“A inibição intelectual não se confunde com a debilidade: a inibição é uma limitação normal das funções do EU, seja por precaução ou por empobrecimento de energia. Sabemos que uma inibição muito precoce pode levar o sujeito a agir de 
forma débil quanto ao conhecimento e, até mesmo, ao saber. Contudo, a debilidade de que se trata - a que se caracteriza por uma posição subjetiva — diz respeito ao desejo; assim, o que está comprometido não é tão somente o EU”. (MIRANDA, 2002, p.22)

Dando suporte a essa concepção está a constatação clínica de que, se numa perspectiva pedagógica e social, uma inibição pode colocar um sujeito até mesmo num nível grave de atraso, por outro lado (o lado clínico), mostra que a debilidade mental e a inibição intelectual parecem advir de status psíquicos diferentes.

Ora, se desde Freud o desagradável do inconsciente é o saber sobre a castração e a sexualidade, o movimento psíquico de inibição é fruto consecutivo de saber o suficiente para desejar não mais saber. Os sujeitos inibidos impedem-se de dar o passo que seu inconsciente já deu — hesitam, duvidam e não agem, a exemplo de Hamlet. A inibição remeteria, portanto, a uma manobra evocada por um saber inconsciente. Já a debilidade mental, conforme enfatizado anteriormente, parece se expressar como a impossibilidade de acessar o saber inconsciente, e não como uma manobra retroativa desde este saber.

A estrada que leva à inibição intelectual tem como ponto de partida um saber inconsciente que já incomodou o sujeito; já a que leva à debilidade mental parece ter partido da impossibilidade de acessar tal saber. Nessa leitura, a debilidade mental se apresentaria como a realização plena de uma condição psíquica presente em todos nós, condição chamada "alienação mental".

É fato conhecido que um bebê humano só sobrevive se houver alguém que cuide dele. Alienado ao desejo deste Outro, eis o cerne da existência de qualquer ser humano, ser falante, ou em outras palavras: “(...) deve-se afirmar que, obra de um animal presa da linguagem, o desejo do homem é o desejo do Outro” (LACAN, 1958/1998, p.634).

A debilidade mental é proposta aqui como uma condição que parece cristalizar a alienação fundamental do sujeito. Desse modo, sendo a alienação ao Outro uma condição de existência, seria possível pensar que há um registro débil em todos nós? Se voltarmos ao conto infantil que nomeia o presente artigo, lembramos que aquele famoso rejeitado por ser um patinho feio de paternidade desconhecida, no final, "ao olhar seu reflexo na água se viu igual aos outros cisnes que ali nadavam”. Será que no lago dos cisnes alienados, o patinho feio chamado débil poderia se reconhecer em nós, seus semelhantes? Com essa analogia sugere-se, como opção a ser investigada, que qualquer um pode ter a debilidade como possibilidade inscrita em seu funcionamento.

Devemos, entretanto, chamar a atenção para que se diferencie uma posição débil (posição de submissão e de não efetivação do desejo próprio) daquela famosa posição de "bobeira ou estupidez" frequentemente presente no neurótico. 
Ambas quase em nada se equivalem, a não ser por retirar um ganho pulsional de um “não saber”. Mannoni (1964) já alertava para a possível confusão feita entre essas duas posições, e assim as diferencia: “A debilidade nada tem a ver com a estupidez, que é antes de tudo uma defesa neurótica” (p.139).

Para finalizar, vale retomar mais uma vez que não só a distinção da estupidez neurótica está em pauta na debilidade, mas principalmente sua confusão diagnóstica com a psicose. Inevitavelmente esses questionamentos se apresentam para um analista que está diante de uma debilidade mental.

Por último, talvez esteja em tempo de reconhecermos a existência da debilidade mental como reflexo de uma posição tomada pelo sujeito do inconsciente. A debilidade não pode mais ser tratada como uma "filha bastarda", como um "patinho feio" a ser rejeitado por ter sua origem em outro campo de estudos (a psiquiatria). Escutar a debilidade mental em sua especificidade, e não como correlata a priori de outras condições já existentes, é não só uma pesquisa a ser feita, mas também um dever ético da psicanálise.

Recebido em 1/9/2008. Aprovado em 22/1/2009.

\section{REFERÊNCIASS}

AMERICAN ASSOCIATION ON MENTAL RETARDATION (AAMR) (2006) Retardo Mental: definição, classificação e sistemas de apoio. Porto Alegre: ArtMed.

AJURIAGUERRA, J. (1978) Manual de psiquiatria infantil. São Paulo: Masson.

CID-10 (2003). Classificação estatística internacional de doenças e problemas relacionados à saúde. São Paulo: Edusp.

CORDIÉ, A. (2003) Los retrasados no existen. Buenos Aires: Nueva Visión.

DALGALARRONDO, P. (2000) Psicopatologia e semiologia dos transtornos mentais. Porto Alegre: ArtMed.

DSM IV (1995) Manual Diagnóstico e Estatístico de Transtornos Mentais. 4 ed. Porto Alegre: Artes Médicas.

FREUD, S. (1926/1998) Inibição, Sintoma e Angústia, in Obras completas, v. XX. Rio de Janeiro: Imago.

KAPLAN, H., I e SADOCK, B. J. (1999) Tratado de Psiquiatria. 6 ed. v. 3. Porto Alegre: Artes Médicas.

LACAN, J. (1958/1998) “Dos princípios da cura e seu poder” in Escritos. Rio de Janeiro: Jorge Zahar.

(1964/1985) O seminário: Os quatro conceitos fundamentais da Psicanálise. Rio de Janeiro: Jorge Zahar. 
LAURENT, E. (1989) “El goce del débil”, in Niños en análisis. Buenos Aires: Paidós.

MANNONI, M. (1964/1999) A criança retardada e a mãe. São Paulo: Martins Fontes.

MIRANDA, E. da R. (2002) "Debilidade mental e estruturas clínicas”. Dissertação de mestrado apresentada ao Programa de Pós-Graduação em Psicanálise da Universidade do Estado do Rio de Janeiro.

SANCHES, D. R. (2008) "Clínica Psicanalítica: a debilidade mental em questão”. Dissertação de mestrado apresentada ao Programa de PósGraduação em Psicologia Clínica da Pontifícia Universidade Católica de São Paulo.

SANTIAGO, A. L. (2005) A inibição intelectual na psicanálise. Rio de Janeiro: Jorge Zahar.

Daniele Rosa Sanches

daniele_rsanches@hotmail.com

Manoel Tosta Berlinck

mtberlin@uol.com.br 